\title{
Research on Establishing System of Integrity for National and State Examination
}

\author{
Daibin Zheng \\ School of Humanity and Law, Wuhan University of Technology, Wuhan, China
}

Keywords: national and state examinations, loss of integrity, honesty, anomie

\begin{abstract}
In recent years, there is a public concern over integrity of state examinations in China. In fact, the efficient operation of examinations is built on faith and integrity. Nowadays, the main reason for anomie of national examinations is the alienation of the main purpose of the examination, lack of severe punishment and execution as well as the lack of fair examination system. To avoid anomie in examinations, so that it further serves to the best of sustainable development, there appears a need for setting up reasonable exam purpose, cultivating integrity self-discipline, accelerating the development and implementation of basic law of examination; overall planning, the establishment of system of integrity for examinations and so on.
\end{abstract}

\section{Introduction}

Examination is not the only way for the country to select and train talents, improve the quality of the citizens, yet it is closely related to citizens' rights to obtain education, grow, succeed etc. Examination is one of the methods widely used to measure educational attainment and its efficient operation built on sustainable honesty. In recent years, much attention has been paid to the state examinations including the entrance examination for college and postgraduate study, as well as social public exams like national civil servant and title level exams in China. It is often said that exam takers break the exam rules and cheat in the examinations. It is now indisputable that the state examination is in crisis in terms of honesty and faith put by people on it. In such circumstances, building fair examination system and strengthening controls over the examination to maintain integrity is worth of great attention.

\section{Integrity is the basis of the effective functioning of the examinations}

The term 'integrity' traditionally has a meaning with long history of origin and rich interpretations in China. The Chinese character pronounced as 'Cheng' in the Chinese version of the word 'integrity' can be found in the Zuo Commentary with an interpretation that there is no cheating involved in integrity. An honest person cheats neither himself nor others. In the book titled Great Learning of Rites, 'integrity' is listed as one of the 'eight rites'. Eight rites are research and investigation, knowledge acquisition, integrity, rectification of heart, cultivation of moral character, management of family, management of state affairs and world peace. 
It is obvious that the term 'Cheng' traditionally possesses an important role in cultivating person's moral values concerning integrity in China. 'Cheng' as the core of moral practice, refers to person's moral character of being trustful and his/her honesty-related principles in life. It focuses on the person's true heart and reflects his/her inner moral appeal towards sincerity. What is more, the term 'cheng' is concerned with both one's own moral standards and standards that he/she would like to develop. Character 'xin' refers to being honest and keeping promises in one's relations with others. It also focuses on the people's behavior, mainly that behavior that can have impact on others. With recent advancements in people's life, the term 'honesty' is shaping richer interpretation.

Honesty is not only a reputation, a resource, but it is also a treasure. A person with high level and record of trustworthiness are always well accepted and respected in the community. On the contrary, a person with less credibility loses a number of opportunities. Honesty extends from being a simple principle of one's life to guideline of interpersonal relationships and goes deep into many areas of social life. In this sense, honesty is not only a personal moral evaluation scale, but it is also a rationale to keep personal and social interests effective. Honesty or dishonesty directly affects current and future situation and development of a person, a team, or even a country. Throughout the development history of China, the terms 'Courtesy and Integrity' can frequently be seen in many important documents. For example, the documents like The Guidelines for Citizen Moral Improvement, The Report of the $18^{\text {th }}$ Congress of the Communist Party of China and the Outline of the Program for the Twelfth Five-year Plan (2010 2015) on the National Economic and Social Development of the People's Republic of China all mention integrity as the priority. Categorized as one of citizens' basic moral norms, integrity holds an important position.

Examinations have been widely used in education, personnel selection and skill identification as a unique social phenomenon of human society. According to its functionality, they are usually classified into two categories: competitive examinations and set standard examinations. Competitive examinations are used to identify, distinguish and select talents. The latter type is used to measure a certain level or a certain standard of people's knowledge, skills and qualification focusing mainly on measurement and evaluation. Generally, an administrative department under the state council implements the state examination. Maintained by the approved national exam institutions, state examination gears to the needs of the public. The enrollment for formal schooling education and civil service or the acquisition of formal schooling certificates, degree certificates, qualification certificates depend on the results of state examination. The state examination is divided into the following types: national education examination, national vocational qualification examination, national professional level examination, and national civil servant employment examination which include college entrance examination and college entrance examination for adults, national postgraduate entrance exam, selftaught higher education examination and national civil servant examination, state judicial examination, etc.

These examinations contain both competitive and set standard examinations. They are oriented to the whole society. The examinations have strong influence on society because results of the exam directly relate to the future and the fate of the examinees.

State examination embraces a wide range of people in its scope and it has a powerful impact on people's life. In its nature, state examination is an important part of political system, because it is an important means of strengthening national cohesion in carrying out the national will and maintaining social stability. National exam presents education opportunities for the people. It is a way for allocation of educational and social resources in the country level. At the time, when the opportunities and resources are relatively limited, creation of a fair examination and bringing trustworthy examination environment is very important. The pursuit of justice is one of eternal value pursuits of human being. Fairness or unfairness decides the validity of the examination. We can say that integrity is the inherent demand of the examination system. Effective operation of national examinations, in its turn, is dependent on the integrity practiced in its management. Fair examination helps us objectively select and employ talents, inspect and evaluate the examinee's true abilities and level. It also helps us effectively develop human resources, optimize the allocation of resources, promote the social, 
political and economic efficiency. Fair examinations directly and forcibly promote and create a favorable social environment.

\section{Examining the main reasons for anomie in the national examination}

Cheating is existent since the first implementation of examination system. Throughout history, whenever there is examination there is temptation of fame and fortune and there are always attempts for cheating. Even in ancient times, there were special books made of paper or silk designed to use in the exam to cheat and entrain. A few candidates used ways of cheating in examination like passing cheating sheets, examination paper, and bringing secret marks into the imperial examinations. So far, the means and ways of cheating and breaking rules in examination emerge in an endless stream in the national exam and the situation is getting worse and worse. Cheating brings great damage to the reputation of the examination system, influences the effectiveness of testing in education as well as affects the quality of personnel training and the development of the national and social integrity. The reasons are as follows:

\subsection{Alienation of the Test Purpose}

Examination aims to measure and identify people's qualities such as knowledge, intelligence, psychological quality, personality traits and other relevant skills. Effect of education is judged and measured by the examination. To a certain extent, the standard score that reflects the examinee's knowledge, abilities and deficiencies helps to identify and distinguish ranks, grades, thus realizing the purpose of 'promoting learning and teaching and educating people through exams'. In the era of knowledge and market economy, national examination determines proper allocation of social resources and thus, serves to the best of the distribution and consumption of economic interests.

Due to the fact that the resources are limited, it is impossible for people to have completely equal opportunities and rights. In such situation, there is a need to find a reasonable, fair and wellestablished solution. In order to achieve proper allocation and stratification of social resources, examination becomes an important measurement. Chinese national examination standardize "livelihood" as its guide rather than follow of interests and hobbies as well as of the heart. If we cannot think out of the box, state examination system will undoubtedly become just exam-oriented and take the wrong turning towards utilitarian.

In fact, recently, some subtle changes in people's thought, moral consciousness and value orientation can be observed. Various values are both interdependent and full of conflicts and value orientation of the whole society tends to be diversified and utilitarian. This irresistible trend directly infects the main purpose of examination. It is not surprising that 'people of honesty' seriously disassociate honest cognition from honest behavior.

\subsection{Insufficient punishment and enforcement for cheating}

The state examination has already been one of the important systems of modern countries' social management. Cheating in the examination, so far, has not been abolished fully and coming to these days, cheating practices are taking more serious look due to lack of punishment and law enforcement. There are some relevant policies and regulations issued in the state policy level like the Constitution, Education Act, Security Act, National Education Examination Regulations and Letter of Commitment of honesty in examinations etc.

Theoretically, it seems easier to apply the punishment, and make penalties more serious. However, in practice, it is not easy to define, control and prevent dishonesty. Up to present days, if the examinee is caught cheating in one subject exam, he or she still can take part in the remaining tests or if the examinee is caught cheating this year, he or she can take the same test next year. The management mode without severe punishment mechanism is just like a heap of loose sand; it cannot play any warning and shocking role in examinees, test agency staff and aid examination institutions. Nowadays, 
cheating has turned from one-person act into the act of organized and premeditated groups. Forms of cheating are no longer in its original forms like passing written messages, peeping, and whispering. Nowadays, advanced communication tools such as wireless headset, mobile phones, and electronic dictionaries are being used as cheating tools. The time span of cheating is extending from 'in the process' cheating to 'before or after the examination' cheating. There are also frequent cases when a different person surrogates actual exam-takers. As a result, a few 'warriors' always appear in the national examinations.

\subsection{The lack of integrity in the examination system}

The integrity of fair examination system directly decides the validity of the credit. At present, due to various reasons, the state examination institutions has not developed a comprehensive way of establishing fair examination archives, real-time dynamic tracking of the examinee's files and examination records. Therefore, the examination institutes can hardly make timely reports to the public regarding the process. In fact, when choosing a standard of behavior, people don't necessarily regulate their own behavior according to ethical norms. This mainly depends on benefits. People are always cautious about their own interests, and they choose to be an honest man on the premise that their interests are satisfied. However, when their interests are damaged or a new temptation emerges, they may give up their moral principles. They are eager to act noble, yet, they do not want to lose their benefits as well. It is true that the lack of enough punishment and integrity in the examination system breeds anomie in examinations to a certain extent.

\section{Strategies to establish fair national examination system}

If fraud motives and behavior in the state examination cannot be rectified or stopped in time, this eventually violates fair and impartial examination standard and brings great damage to the reputation of the national examination affecting healthy competition over social order. The pursuit of science, objectiveness and fairness are values sought in the examination. It has currently become an important and urgent task to carry out the comprehensive improvement in the national examination environment.

\subsection{Establishing reasonable view of examination purpose and cultivating integrity- based self-discipline}

Examination is not evaluation; it is one of the means of evaluation. The ultimate purpose of the test is to lead people to the way of education. People rationally compete based on examination, thus they try to build solid knowledge foundation and skills by studying and working hard. At the same time, difficulties of hard work and study foster strong will in people, cultivate good moral, educate people to be real and honest. Examinations, in its turn, motivate people to learn and advance bravely. It also hastens the emergence of talents, facilitates the harmonious development of economy and society. Additionally, it can also purify the mind and teach people to distinguish truth from false, develop spirit and enable people to get pleasure from studies, bring cheerfulness and improve social life and advance all-round development of personality [1]. All these serve to realize proper selection of specialized personnel possessing talent and political integrity, promote the development of human resources, upgrade the ideological and ethical standards, improve cultural and scientific levels of people and meet the needs of China's socialism-based modernization.

To nurture honesty in people's heart and to strengthen honesty through education cultivates consciousness of self-discipline. As individuals, we may not change many things but can control ourselves as much as possible, and look on honesty as basic personal moral bottom line. Personal integrity is the foundation of harmonious interpersonal relations, steady economic development and social stability. Every person is responsible for his/her own integrity. Only after we examine our 
behaviors and measure whether our actions are consistent with our values, purpose and promise, then we can contribute to social integrity. By strengthening self-discipline and risk consciousness of stakeholders of the national examination, we can guide them to correctly understand the real purpose of examination system.

\subsection{Accelerating the establishment and implementation of examination law}

There is a need for strictly carrying out control, establish and implement the basic rules for examination through established laws. Examination law not only establishes proper classification and nature of the examination but also it adjusts the relations in the examination, regulates it and delimitates cheating. The rules and regulations of the examinations have to be revised and advanced at various levels based on the examination law. Following examination law, relevant provisions can be added to 'criminal law'. Cheating cases of the examination should be included in the scope that criminal law revises. There is also a need to increase the punishment to cheating in the exam. At the same time, state should seek reasonable cohesion of 'Parent Law' and 'Sub-law' of the examination system, unveil specific legal texts for state examination, fill the defects of legislative technology of the national test, and produce the effectiveness of the laws and regulations to the maximum. On the one hand, punishing cheating in the national examination by law will increase the cost of cheating. According to General Theory of Law, when the cost of cheating becomes five times greater than that of its benefit cost, cheating can be restrained. When the cost of cheating becomes ten times greater than that of its benefit cost, cheating will be controlled or forestalled. On the other hand, the country should carry out the rigid cost system and make the system strongly constrain behavior, thus effectively maintaining management mechanism. Stakeholders of state exams are usually responsible for maintaining social justice and organizing fair examination system. Therefore, they have to act strictly and fairly. Chief criminal, organizing groups as well as intermediary person concerning exam cheating and stealing, personnel revealing test questions, replacing actual exam-takers, civil servants with malfeasance should be severely punished. Behaviors that produce serious consequences, great damage, extremely bad influence, seriously undermine the testing process by using mean tricks, should be investigated according to law and should be punished with aggravated punishments. Responsible people who do not put punishment into practice or refuse to practice should also be severely punished. It is believed that only under the deterrence of law can reduce cheating in the exam to a minimum. This makes responsible people pay for dishonesty, and thus creates a fair examination.

\subsection{The establishment of fair examination system through overall planning}

A comprehensive overall planning can build fair examination system. Records, collection and management of examination information are the basis of building fair examination system. Learning from the experience of some advanced countries and relevant organizations, we have to formulate personal credit system in establishing fair examination systems. On the macro level, there should be a built system to deal with the role or division of examination institutions, the establishment and application of credit information database, effective cohesion and sharing of credit platforms among the types of state examination or between national examination and non-state examination. On the micro level, there is a need that we record 'footprint' left by the stakeholders in the national examination completely, accurately and timely and establish the archive management. After carefully studying and clarifying standards and the degree of cheating behaviors, candidate's personal credibility file on exam can be used as an important document in the future. Therefore, the establishment of candidates' credit file on exam will play a decisive role in personnel evaluation, selection and employment at the time when there is a need for evaluating, choosing and employing people into different positions. 


\section{References}

[1] Chun-yang, L.," Construction and exploration of integrity examination ethos evaluation system [J]", Journal of Shenyang Institute of Engineering (Social Sciences) Vol. 1 (2012) , p. 37.

[2] Davidsohn, S., Ance Introduction to the New Testament, Containing an Examination of the Most Important Questions Relating to the Authority, Interpretation and Integrity of the Canonical Books with Reference to the Latest Inquiries: Sam. Bagster, 1848.

[3] Habanek, D.V.," An examination of the integrity of the syllabus", College Teaching Vol. 53, No. 2 (2005), p. 62-64.

[4] JIA, T., L. ZHANG, P. WANG, and W. ZHOU," A Probabilistic View of the Research on Undergraduates' Examination Integrity State [J]", Journal of Mianyang Normal University Vol. 5, 2008, p. 3.

[5] Neuman, G.A., and R. Baydoun," An empirical examination of overt and covert integrity tests", Journal of Business and Psychology Vol. 13, No. 1, 1998, p. 65-79.

[6] Oluwatelure, T.A.," Perception of Academic Integrity Violation and Examination Issues by Selected Members of the University Community", Pak. J. Soc. Sci Vol. 5, No. 7, 2008, p. 686-690.

[7] Salami, A., "Examination malpractice and the integrity of examination credentials", A Paper Presented at the 12th Annual Conference of AEAA in Accra, 1994.

[8] Woolley, R.M., and A.R. Hakstian," An examination of the construct validity of personalitybased and overt measures of integrity", Educ Psychol Meas Vol. 52, No. 2, 1992, p. 475-489.

[9] Woolley, R.M., and A.R. Hakstian," An examination of the construct validity of personalitybased and overt measures of integrity", Educ Psychol Meas Vol. 52, No. 2, 1992, p. 475-489. 